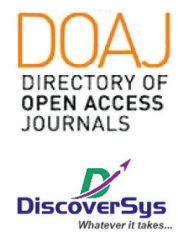

Published by DiscoverSys

\section{Hubungan resting metabolic rate (RMR) dan komposisi tubuh dengan kadar $\mathrm{HbA} 1 \mathrm{c}$ pada obesitas}

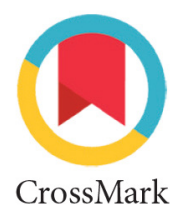

CrossMark

\author{
Inggrid Lovita ${ }^{1 *}$, Meita Hendrianingtyas ${ }^{2}$, Ria Triwardhani ${ }^{2}$
}

\begin{abstract}
Background: Obesity occurs due to an imbalance intake and energy expenditure. The cause of obesity is low energy expenditure whereas the resting metabolic rate (RMR) is the largest component of energy expenditure of the body. The factors that influence RMR are body composition, age, sex and hormonal status. Body composition measured as fat mass and free fat mass (FFM). Body fat increase in obesity can cause insulin resistance which will increase blood glucose levels. This study aims to determine the correlation between RMR and body composition (fat mass and FFM) with $\mathrm{HbA1c}$ levels increase as a parameter of diabetes mellitus in obesity.
\end{abstract}

Methods: Cross sectional study design to 38 subjects young adults obese. Resting metabolic rate and body composition (fat mass and FFM) measured with Omron Karada scan HBF 375 . HbA1c measured with ion-exchange HPLC method. Statistical analysis using the Spearman's correlation test $(p<0.05)$

Result: $\mathrm{HbA1c}$ mean of $5.4 \%$ is still a normal value of HbA1c. There were no correlation between RMR and HbA1c $(p=0.768)$, fat mass with $\operatorname{HbATc}(p=0.102)$ and FFM with $\operatorname{HbA1c}(p=0.843)$. Conclusion: RMR and body composition (fat mass and FFM) are not associated with $\mathrm{HbA1c}$ levels in obese young adults.

Keywords: resting metabolic rate, fat mass, free fat mass, HbA1c, obesity

Cite This Article: Lovita, I., Hendrianingtyas, M., Triwardhani, R. 2019. Hubungan resting metabolic rate (RMR) dan komposisi tubuh dengan kadar HbA1c pada obesitas. Intisari Sains Medis 10 (1): 218-222. D0I: 10.1556/ism.v10i1.345

\title{
ABSTRAK
}

'Program Pendidikan Dokter Spesialis, Bagian Patologi Klinik, Fakultas Kedokteran Universitas Diponegoro, Rumah Sakit Umum Pusat dr. Kariadi, Semarang ${ }^{2}$ Bagian Patologi Klinik, Fakultas Kedokteran Universitas Diponegoro, Rumah Sakit Umum Pusat dr. Kariadi, Semarang

\footnotetext{
* Korespondensi : Inggrid Lovita; Program Pendidikan Dokter Spesialis, Bagian Patologi Klinik, Fakultas Kedokteran Universitas Diponegoro, Rumah Sakit Umum Pusat dr. Kariadi, Semarang; inggridsidik@gmail.com
}

Diterima : 07-11-2018 Disetujui : 26-03-2019 Diterbitkan : 01-04-2019

Pendahuluan: Obesitas terjadi karena ketidakseimbangan asupan dengan pengeluaran energi. Penyebab obesitas adalah rendahnya pengeluaran energi dimana resting metabolic rate (RMR) merupakan komponen pengeluaran energi terbesar oleh tubuh. Faktor yang mempengaruhi RMR adalah komposisi tubuh, usia, jenis kelamin dan status hormonal. Komposisi tubuh yang diukur yaitu fat mass (FM) dan free fat mass (FFM). Peningkatan jumlah lemak tubuh pada obesitas dapat menimbulkan resistensi insulin yang akan meningkatkan kadar glukosa darah. Penelitian ini bertujuan untuk mengetahui hubungan RMR dan komposisi tubuh (FM dan FFM) dengan peningkatan kadar HbA1c sebagai parameter diabetes melitus pada obesitas.

Kata Kunci: fat mass, free fat mass, $\mathrm{HbA1c}$, obesitas, resting metabolic rate Site Pasal Ini: Lovita, I., Hendrianingtyas, M., Triwardhani, R. 2019. Hubungan resting metabolic rate (RMR) dan komposisi tubuh dengan kadar HbA1c pada obesitas. Intisari Sains Medis 10 (1): 218-222. D0l: 10.1556/ism.v10i1.345

\section{PENDAHULUAN}

Obesitas adalah suatu keadaan di mana terjadi penimbunan lemak tubuh berlebih yang menyebabkan berat badan tubuh seseorang jauh di atas normal. Obesitas terjadi saat adanya ketidakseimbangan antara asupan (intake) dengan
Metode: Ini merupakan penelitian potong lintang pada 38 subjek dewasa muda dengan obesitas. Pengukuran RMR dan komposisi tubuh (FM dan FFM) menggunakan Omron Karada scan HBF 375. Pengukuran HbA1c menggunakan metode ion-exchange HPLC. Analisis statistik menggunakan uji korelasi Spearman's. $(p<0.05)$ Hasil: Rerata HbA1c 5.4\% merupakan nilai HbA1c normal. Tidak terdapat hubungan antara HbA1C dengan RMR $(p=0.768)$, FM ( $p$ $=0.102)$ dan FFM $\quad(p=0.843)$.

Simpulan: RMR dan komposisi tubuh (FM dan FFM) tidak berhubungan dengan kadar HbA1c pada dewasa muda dengan obesitas. pengeluaran energi (expenditure). Penyebab obesitas adalah multifaktorial, baik faktor individual maupun faktor lingkungan. ${ }^{1}$ Obesitas merupakan faktor risiko utama untuk penyakit kronis yang berhubungan dengan sindroma metabolik, termasuk diabetes mellitus tipe 2 , penyakit jantung, 
hipertensi, stroke, dan bentuk-bentuk tertentu dari kanker. ${ }^{2,3}$

Prevalensi obesitas umumnya didapatkan dengan menilai status gizi menggunakan indeks massa tubuh (IMT), yang didefinisikan sebagai berat dalam kilogram dibagi dengan kuadrat tinggi dalam meter $(\mathrm{kg} / \mathrm{m} 2)$. Berdasarkan WHO, IMT $>30$ menandakan individu tersebut termasuk ke dalam golongan obesitas. Klasifikasi obesitas di Indonesia mengikuti kriteria dari Riskesdas yaitu individu dengan IMT $\geq 27^{3-5}$

Obesitas terjadi karena ketidakseimbangan energi dalam jangka waktu lama dimana asupan energi (dalam bentuk makanan) lebih besar dibandingkan pengeluarannya. Salah satu cara untuk mencegah terjadinya obesitas adalah dengan mengatur pengeluaran energi. Pengeluaran energi (energy expenditure) sendiri dibagi menjadi beberapa komponen. Komponen terbesar dari pengeluaran energi adalah basal metabolic rate (BMR), yaitu hampir 60-70\% dari total pengeluaran harian. Basal metabolic rate dapat secara tepat menggambarkan total energy expenditure namun pengukuran $B M R$ sendiri relatif sulit dilakukan, maka untuk mengukur energy expenditure biasanya menggunakan resting metabolic rate (RMR) yang diukur pada pagi hari sebelum seseorang melakukan aktivitas fisik dan setelah puasa selama 10 sampai 12 jam. ${ }^{6-8}$

Terdapat faktor-faktor yang mempengaruhi nilai $R M R$ diantaranya ukuran tubuh, komposisi tubuh, usia, jenis kelamin, status hormonal, dan jenis makanan. Komposisi tubuh yang diukur yaitu massa lemak tubuh atau fat mass (FM) dan massa tubuh bebas lemak atau free fat mass (FFM). Free fat mass merupakan metabolisme aktif pada jaringan tubuh yang merupakan faktor penentu dari $R M R$. Peningkatan aktivitas fisik dapat menyebabkan peningkatan pengeluaran energi dan mempromosikan pertumbuhan otot, sehingga meningkatkan FFM. Free fat mass merupakan penentu utama metabolisme basal, maka penurunan FFM dapat menyebabkan penurunan metabolisme basal, yang nantinya dapat berefek pada terhambatnya pengeluaran energi. Pada orang obesitas, penurunan aktivitas fisik dapat menurunkan pengeluaran energi kurang dari asupan makanan, yang berimbas pada peningkatan berat badan. Salah satu penyebab obesitas adalah rendahnya pengeluaran energi, dimana $R M R$ merupakan komponen pengeluaran energi yang terbesar oleh tubuh. ${ }^{6,7,9}$

Faktor resiko diabetes melitus yaitu usia, obesitas, distribusi lemak tubuh, kurangnya aktifitas jasmani dan hiperinsulinemia. Semua faktor ini berinteraksi dengan beberapa faktor genetik yang berhubungan dengan terjadinya diabetes melitus tipe 2. Peningkatan kadar glukosa darah dalam tubuh tersebut akan berdampak pada peningkatan kadar HbAlc. ${ }^{10}$ Secara teori, peningkatan jumlah lemak tubuh pada obesitas dapat menimbulkan resistensi insulin pada seseorang, padahal jika terjadi resistensi insulin secara berkelanjutan maka akan menyebabkan peningkatan kadar glukosa darah, yang merupakan tanda pada sindroma metabolik yang mengarah pada penyakit diabetes. ${ }^{10,11} \mathrm{Hal}$ ini diperkuat dengan penelitian yang dilakukan oleh Innocent $\mathrm{O}$ et al pada tahun 2013 yang menunjukkan adanya hubungan positif antara obesitas dengan kadar gula darah. ${ }^{10,11}$

Kontrol glikemik merupakan salah satu hal penting dalam evaluasi pasien DM. Salah satu parameter kontrol glikemik adalah kadar hemoglobin terglikasi (HbAlc). ${ }^{13,14}$ Komite ahli dari the American Diabetes Association (ADA) dan the European Association for the Study of Diabetes (EASD) kemudian merekomendasikan penggunaan HbAlc untuk diagnosis diabetes melitus, dan pada tahun 2010 ADA memasukkan HbAlc ke dalam kriteria diagnosis diabetes melitus. ${ }^{14,15}$ Manfaat HbAlc selama ini lebih banyak dikenal untuk menilai kualitas pengendalian glikemik jangka panjang dan menilai efektivitas terapi, namun saat ini HbAlc bukan hanya untuk pemantauan, tetapi juga bermanfaat dalam diagnosis ataupun skrining diabetes melitus tipe 2. ${ }^{14,15}$ Menurut konsensus PERKENI tahun 2015 kadar HbAlc normal kurang dari 5,7\%, prediabetes $5,7 \%-6,4 \%$, dan termasuk kedalam diabetes jika kadar nya lebih besar sama dengan $6,5 \% .^{12}$

Beberapa penelitian tentang hubungan $R M R$ dan komposisi tubuh telah dilakukan, salah satunya penelitian yang dilakukan oleh Septiani M et al pada tahun 2011, namun sampel penelitian yaang diperiksa adalah obesitas pada anak anak, sehingga pada penelitian selanjutnya perlu dilakukan penelitian tentang hubungan RMR dan komposisi tubuh dengan sampel obesitas pada dewasa. ${ }^{8}$ Penelitian terdahulu menunjukkan bahwa obesitas merupakan prediktor kuat perkembangan penyakit ini. Sekitar $85 \%$ pasien dengan DM tipe 2 mengalami obesitas. ${ }^{8}$ Alberti george et al menemukan bahwa anak-anak yang mengalami obesitas memiliki risiko terjadi gangguan metabolik termasuk diantaranya DM tipe 2.

Hubungan Resting metabolic rate dan parameter komposisi tubuh (FM dan FFM) pada obesitas dengan peningkatan kadar $\mathrm{HbAlc}$ sebagai parameter diabetes melitus diharapkan dapat diketahui sehingga dapat menekan angka terjadinya komplikasi pada obesitas. ${ }^{89}$ Tujuan dari penelitian ini adalah untuk mengetahui hubungan 
resting metabolic rate (RMR) dan komposisi tubuh (FM dan FFM) dengan kadar HbAlc pada obesitas.

\section{METODE}

Penelitian ini merupakan penelitian korelasional yang dilakukan secara cross sectional,. Penelitian ini dilakukan di Fakultas Kedokteran Universitas Diponegoro, Semarang pada bulan Maret 2018. Pemilihan subjek penelitian menggunakan consecutive sampling yang bersedia mengikuti penelitian dibuktikan dengan penandatanganan lembar inform consent. Pengukuran RMR dan komposisi tubuh menggunakan alat Karada Scan Omron HBF 375. Alat ini adalah alat ukur lemak yang mengukur persen lemak tubuh dengan menggunakan metode Bioelectrical impedance. Otot pembuluh darah dan tulang adalah jaringan tubuh yang kandungan airnya tinggi sehingga dapat menghantarkan listrik yang sangat kecil ke dalam tubuh yaitu sekitar $50 \mathrm{kHz}$ dan kurang dari $500 \mathrm{~mA}$ untuk mengetahui jumlah jaringan lemak dalam tubuh. Pengukuran RMR dilakukan pada pagi hari sebelum subjek penelitian melakukan aktivitas fisik dan setelah puasa selama 10-12 jam.

Pemeriksaan HbAlc dilakukan di Laboratorium Klinik swasta di Semarang menggunakan metode ion-exchange HPLC. Metode cation-exchange chromatography didasarkan pada perbedaan beban antara fase bergerak dan fase statis, Metode ini mampu mendeteksi hemoglobin abnormal dan memiliki reprodusibilitas yang baik dengan $\mathrm{CV}<1 \%$, namun kelemahan metode ini adalah memerlukan alat yang khusus, tenaga yang ahli dan waktu yang lama sehingga tidak bisa digunakan di rumah sakit dengan sampel pemeriksaan HbA1c yang banyak.

Ethical clearance dikeluarkan dari bagian komisi etik penelitian kesehatan Fakultas Fedokteran Universitas Diponegoro - RSUP. Dr. Kariadi Semarang dengan nomor 119/EC/FK-RSDK/ III/2018.

Data pemeriksaan laboratorium dikumpulkan dan diolah menggunakan program komputer.

Tabel 1. Karakteristik dasar subjek

\begin{tabular}{lcc}
\hline \multicolumn{1}{c}{ Variabel } & Rerata \pm SD & $\begin{array}{c}\text { Median } \\
\text { (min - maks) }\end{array}$ \\
\hline Usia (tahun) & $20.1 \pm 1.3$ & $20(18-23)$ \\
IMT $\left(\mathrm{kg} / \mathrm{m}^{2}\right)$ & $31.7 \pm 3.7$ & $30.4(27-38.7)$ \\
RMR $(\mathrm{kkal} / \mathrm{kg})$ & $1772.9 \pm 283.8$ & $1777(1313-2300)$ \\
FM $(\mathrm{kg})$ & $33.1 \pm 4.4$ & $33.2(25-42.4)$ \\
FFM $(\mathrm{kg})$ & $55.0 \pm 14.9$ & $54.4(31.4-84.3)$ \\
HbAlc $(\%)$ & $5.4 \pm 0.2$ & $5.6(5.1-6.0)$ \\
\hline
\end{tabular}

Dilakukan uji normalitas data dengan Saphiro-Wilk. Data yang terdistribusi normal dilakukan analisis statistik karakteristik dasar subjek menggunakan uji korelasi pearson sedangkan hubungan RMR, FM dan FFM terhadap HbA1c dianalisis dengan uji korelasi spearman's. Uji statistik dianggap bermakna jika $\mathrm{p}<0.05$.

\section{HASIL}

Hasil penelitian terhadap sampel dewasa muda dengan (IMT >27) selama periode penelitian di dapatkan subjek penelitian yang memenuhi kriteria inklusi sebanyak 38 orang yang terdiri dari 27 (62.1\%) subjek laki-laki dan 11 (37.9\%) subjek perempuan. Rerata usia 20 tahun, dengan rerata IMT $31.7 \mathrm{~kg} / \mathrm{m}^{2}$ yang termasuk dalam kategori obesitas.

Pemeriksaan yang dilakukan meliputi pengukuran antropometri, RMR, komposisi tubuh (FM dan FFM) dan kadar HbAlc. Hasil rata-rata HbA1c subjek penelitian adalah 5.4\%. Karakteristik dasar subjek dari hasil pengukuran antropometri dan komposisi tubuh ditampilkan pada Tabel 1.

Faktor-faktor yang mempengaruhi nilai $R M R$ diantaranya ukuran tubuh, komposisi tubuh (FM dan FFM), usia, jenis kelamin, status hormonal, dan jenis makanan. Analisa data untuk subjek lakilaki dan perempuan sejak awal sudah dipisahkan karena komposisi tubuh dan RMR pada laki-laki dan perempuan berbeda. Karakteristik subjek dari hasil pengukuran antropometri dan komposisi tubuh pada laki-laki dan perempuan ditampilkan pada Tabel 2.

Pada Tabel 3 dapat dilihan bahwa dari hasil uji korelasi spearman tidak terdapat korelasi antara HbAlc dengan RMR ( $p=0.768), F M(p=0.102)$, dan FFM ( $p=0.843)$.

\section{PEMBAHASAN}

\section{Komposisi tubuh}

Pada penelitian ini, didapatkan variasi komposisi tubuh pada subyek penelitian, 38 subyek penelitian yang telah bersedia mengikuti penelitian, rerata umur subyek penelitian baik laki-laki dan perempuan adalah 20 tahun dapat dilihat pada Tabel 1.

Rerata IMT pada laki-laki sebesar $32.5 \pm 3.9$ $\mathrm{kg} / \mathrm{m}^{2}$ sedangkan pada perempuan $30.8 \pm 3.5$ $\mathrm{kg} / \mathrm{m}^{2}$. IMT merupakan cara termudah untuk memperkirakan status gizi seseorang yakni obesitas, normal, atau gizi kurang. Selain itu IMT juga berkorelasi dengan masa lemak tubuh. Pengukuran ini sangat sederhana dan dapat digunakan dalam penelitian populasi berskala besar.

Rerata FM pada perempuan yaitu $36.3 \pm 3.5 \mathrm{~kg}$, 
Tabel 2. RMR dan komposisi tubuh menurut jenis kelamin.

\begin{tabular}{ccc}
\hline \multirow{2}{*}{ Variabel } & \multicolumn{2}{c}{ Rerata \pm SD } \\
\cline { 2 - 3 } & Laki- laki & Perempuan \\
\hline IMT $\left(\mathrm{kg} / \mathrm{m}^{2}\right)$ & $32.5 \pm 3.9$ & $30.8 \pm 3.5$ \\
RMR/hari $(\mathrm{kkal})$ & $1936 \pm 244.7$ & $1528.7 \pm 136.3$ \\
FFM $(\mathrm{kg})$ & $63.4 \pm 13.2$ & $42.5 \pm 7.3$ \\
FM $(\mathrm{kg})$ & $31.4 \pm 3.7$ & $36.3 \pm 3.5$ \\
\hline
\end{tabular}

Tabel 3. Korelasi RMR, FM dan FFM dengan HbA1c.

\begin{tabular}{|c|c|c|c|}
\hline \multirow{2}{*}{ Variabel } & \multicolumn{2}{|c|}{ HbA1c } & \multirow{2}{*}{ Keterangan } \\
\hline & $\mathbf{p}^{*}$ & $\mathbf{R}$ & \\
\hline RMR (kkal) & 0.768 & 0.057 & Tidak berhubungan \\
\hline FM $(\mathrm{kg})$ & 0.102 & 0.310 & Tidak berhubungan \\
\hline FFM $(\mathrm{kg})$ & 0.843 & 0.038 & Tidak berhubungan \\
\hline
\end{tabular}

$\left.{ }^{\star}\right)$ Korelasi Spearman obesitas, peningkatan jumlah lemak tubuh pada obesitas dapat menimbulkan resistensi insulin pada seseorang. ${ }^{13}$ Resistensi insulin secara berkelanjutan dapat menyebabkan peningkatan kadar glukosa darah, yang merupakan tanda pada sindroma metabolik yang mengarah pada penyakit diabetes. Kadar glukosa darah dapat dilihat dari nilai $\mathrm{HbAlc}$ yang diperiksa. Menurut konsensus PERKENI tahun 2015 kadar HbAlc normal kurang dari 5.7\%, prediabetes $5.7 \%-6.4 \%$, dan termasuk kategori diabetes jika kadar nya lebih besar sama dengan $6.5 \% .^{13}$

Menurut penelitian Septiani $\mathrm{M}$ et al..$^{15}$ tahun 2011 didapatkan RMR pada obesitas lebih rendah daripada normal. Pada penelitian ini RMR berhubungan dengan berat badan dan FFM. Studi yang dilakukan oleh Hasanuddin et al. pada tahun 2011 di Makassar mengindikasikan bahwa kadar HbAlc rata-rata berdasarkan IMT pada pria obesitas lebih tinggi dibandingan dengan pria nonobesitas. Penelitian yang dilakukan oleh Senechal M et al. pada tahun 2013 tentang hubungan perubahan distribusi komposisi tubuh dengan perubahan pada HbAlc didapatkan hasil adanya hubungan antara kadar HbAlc dengan komposisi tubuh. Sedangkan pada penelitian ini dari hasil uji korelasi spearman tidak terdapat hubungan antara RMR, dengan $\mathrm{HbAlc}$ dan tidak terdapat hubungan antara komposisi tubuh (FM dan FFM) dengan kadar HbAlc. ${ }^{14}$

Pada keadaan obesitas terjadi peningkatan jaringan adiposa yang biasanya diikuti keadaan resistensi insulin. Resistensi insulin merupakan suatu fase awal abnormalitas metabolik sampai terjadinya intoleransi glukosa. Reseptor adrenergik yang terdapat di jaringan adiposa termasuk lemak di perut dapat mempengaruhi pengaturan lipolisis dan suhu. ${ }^{14,15}$ Pada kondisi awal intoleransi glukosa, insulin yang diproduksi sel $\beta$ pankreas masih dapat melakukan kompensasi dengan meningkatkan sekresi insulin. Keadaan hiperinsulinemia ini dapat mempertahankankadarglukosa darah padakeadaan normal. Sensitivitas terhadap insulin dan sekresi insulin merupakan dua kondisi yang berlawanan dan berkaitan secara proporsional. Makin rendah sensitivitas insulin (makin tinggi resistensi insulin) makin banyak insulin yang disekresi. Hasil dari keseimbangan antara sensitivitas insulin dan sekresi insulin adaalah konstan dan digunakan sebagai standar dari glucose disposition index. Apabila sensitivitas insulin menurun, sekresi sel $ß$ pankreas harus meningkat untuk mempertahankan glucose disposition index..$^{14,15}$

Kegagalan sel $ß$ pankreas menyebabkan sekresi insulin tidak adekuat, sehingga terjadi transisi dari kondisi resistensi insulin ke diabetes yang 
bermanifestasi secara klinis. Sehingga pada awal proses penyakit berlangsung tanpa gejala, sampai terjadi kegagalan fungsi sel $\beta$ pankreas. ${ }^{15}$ Keadaan ini yang menyebabkan pada subjek penelitian belum terdapat peningkatan kadar HbAlc karena gangguan metabolik sudah terjadi namun belum terdapat peningkatan kadar glukosa darah, sehingga pada penelitian ini tidak terdapat hubungan RMR dan komposisi tubuh (FM, dan FFM) dengan kadar HbAlc pada subjek penelitian.

\section{Simpulan}

Tidak terdapat hubungan antara RMR dan komposisi tubuh (FM dan FFM) dengan kadar $\mathrm{HbA1c}$. Penelitian ini memiliki keterbatasan dalam variasi karakteristik subjek penelitian dimana jumlah sampel laki-laki dan perempuan tidak sama besar, juga keterbatasan waktu dan biaya tidak menggunakan subjek dengan IMT normal sebagai kontrol, sehingga peneliti tidak dapat membandingkan hasil penelitian pada keadaan normal dan obesitas.

\section{REFERENSI}

1. Swinburn B, Caterson I, Seidell J, James WP. Diet, nutrition and the prevention of excess weight gain and obesity. Public Health Nutr. 2004;7(1A):123-46.

2. Badan Penelitian dan Pengembangan Kesehatan Kementerian Kesehatann RI. Riset Kesehatan Dasar Riskesdas 2013. Available at: http://www.depkes.go.id/resources/download/ general/Hasil\%20Riskesdas\%202013.pdf

3. Ellulu M, Abed Y, Rahmat A, Ranneh Y, Ali F. Epidemiology of obesity in developing countries: challenges and prevention. Glob Epidemi Obes. 2014;2:2. DOI: 10.7243/20525966-2-2.

4. World Health Organization. Global Strategy on Diet, Physical Activity, and Health. 2003.

5. Pereira PF, Serrano HM, Carvalho GQ, Ribeiro SM, Peluzio Mdo C, Franceschini Sdo $\mathrm{C}$ et al. Measurements of location of body fat distribution: an assessment of colinearity with body mass, adiposity and stature in female adolescents. Rev Paul Pediatr. 2015;33(1):6371. DOI: $10.1016 /$ j.rpped.2014.11.011.
6. Saudek CD, Herman WH, Sacks DB, Bergenstal RM, Edelman D, Davidson MB. A new look at screening and diagnosing diabetes mellitus. J Clin Endocrinol Metab. 2008;93(7):2447-53. DOI: $10.1210 /$ jc.2007-2174.

7. Harefa E. Peran HbAlc dalam skrining dan diagnosis diabetes melitus. Informasi Laboratorium Klinik Prodia. 2010.

8. Paputungan SR, Sanusi H. Peranan Pemeriksaan Hemoglobin A 1c pada Pengelolaan Diabetes Melitus. Cermin Dunia Kedokteran. 2014;41(9):650-5.

9. Ghazanfari Z, Haghdoost AA, Alizadeh SM, Atapour J, Zolala F. A Comparison of HbAlc and Fasting Blood Sugar Tests in General Population. Int J Prev Med. 2010;1(3):187-94.

10. World Health Organization. Obesity and overweight. 2016.

11. Anonim. What is HbAlc? - Definition, Units, Conversion, Testing \& Control.. Available at: http://www.diabetes.co.uk/what-is-hbalc. html. [cited 2017 Feb 18]

12. Stensel DJ, Lin FP, Nevill AM. Resting metabolic rate in obese and nonobese Chinese Singaporean boys aged 13-15 y. Am J Clin Nutr. 2001;74(3):369-73.

13. Septiani M, Mexitalia M. Hubungan Antara Resting Metabolic Rate (RMR) Dengan Komposisi Tubuh Pada Anak Obesitas. Semarang:Universitas Diponegoro; 2011.

14. Perkumpulan Endokrinologi Indonesia. Konsensus pengelolaan dan pencegahan diabetes melitus type 2 di Indonesia. 2015.

15. Zimmet P, Alberti KG, Kaufman F, Tajima N, Silink M, Arslanian S et al. The metabolic syndrome in children and adolescents - an IDF consensus report. Pediatr Diabetes. 2007;8(5):299-306. DOI: $10.1111 /$ j.13995448.2007.00271.x.

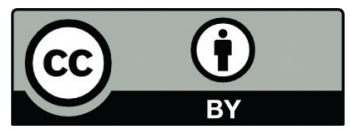

This work is licensed under a Creative Commons Attribution 